\title{
Oral manifestation of thalassemia $\beta$ mayor: case study
}

\author{
Haris B. Widodo, ${ }^{*}$ Aisya E. Maharani²
}

${ }^{1}$ Department of Oral Biology, Faculty of Medicine, Jenderal Soedirman University, Purwekerto, Indonesia

${ }^{2}$ Integration clinic Dental Hospital, Jenderal Soedirman Univrsity, Purwekerto, Indonesia

${ }^{*}$ Correspondence to:

aisya.erryza@gmail.com

Received: 5 November 2018 Revised: 20 February 2019 Accepted: 7 March 2019 Available Online: 1 May 2019

\section{Abstract}

Objective: The condition caused patient with thalassemia b major require blood transfusion. The purpose of this paper is to describe an oral manifestation of thalassemia $\beta$ major.

Methods: Intraoral examination showed pale oral mucose (purplish), profound caries on 85th teeth exposed to pulp, overbite $4 \mathrm{~mm}$, overjet $3 \mathrm{~mm}$, deep palatum and the extraoral examination showed

\section{special face shape.}

Results: Based on the radiographic results it can be seen that patients with thalassemia have skeletal class II tendency and there is more anterior or protusive appearence of maxillary growth.

Conclusion: Patients with thalassemia have skeletal class II tendency and there is more anterior or protusive appearence of maxillary growth.

Keywords: Hemoglobin, Oral manifestation, Thalassemia $\beta$ mayor

Cite this Article:Widodo HB, Maharani AE. 2019. Oral manifestation of thalassemia $\beta$ mayor: case study. Journal of Case Reports in Dental Medicine. 1(2): 32-35. D0l: 10.20956/jcrdm.v1i2.90

\section{Introduction}

Thalassemia is a blood disorder which is an abnormality of the hemoglobin form. Thalassemia comes from the greek word "Thalasso" which means sea and "-emia" which means blood. Thalassemia was first discovered by a doctor named Thomas B. Cooley in 1925 in the Mediterranean region, from children who experience anemia with swollen lymph. Thalassemia occurs because of the failure to form one of the four hemoglobin-forming amino acid chains so that hemoglobin is not fully formed. Incomplete hemoglobin will cause an imperfect red blood cell form and create red blood cells that are easily damaged or less than 120 days old. ${ }^{1}$

Thalassemia consists of two types, thalassemia $\alpha$ and thalassemia $\beta$. Thalassemia $b$ is type of thalassemia that occurs heredity that is autosomal recessive because of the mutation of genes on chromosome 11. This mutation causes abnormalities in the hemoglobin chain. The prevalence of death of patients with thalassemia $\beta$ in the Mediterranean community in 2013 has reached 25.000 pupils. This number has decreased by 11.000 people from 1990 . Thalassemia is caused by mutations from chromosome 16 for thalassemia $\alpha$ and chromosome 11 for thalassemia $\beta$. Couples who have a thalassemia gene will have a high likelihood of having offspring with thalassemia. ${ }^{1}$

Clinically, thalassemia is divided into 3 types, namely thalassemia major, thalassemia intermedia, and thalassemia minor (triat). Thalassemia major is thalassemia which occurs when both parents have thalassemia carrying properties. Children with thalassemia major will be born under normal conditions. Symptoms of a new blood deficiency will appear at 3-18 months of age marked by chronic progressive hemilytic anemia for 6 months and can cause swelling of the pancreas gland. Thalassemia $\beta$ major is the worst form of this disease. Patients will experience severe anemia with hematocrit level less than $20 \%$ so that blood transfusions are needed by these patients. Symptoms that often occur from patients with thalassemia $\beta$ major is the enlargement of the lymph and liver, stunted growth due to abnormalities in the bone. ${ }^{2}$ Abnormalities of bone occur during bone osteogenesis due to hyperactivity of the spinal cord which will lead to excessive growth of frontal, parietal, zygomatic, and maxillary bone protusive. ${ }^{3}$

The process of oxification or osteogenesis consists of two stages which is involving the formation of a proteinaceus organic matrix which later will be calcified. Mature and developing bones contain four types of cells namely osteogenic cells (osteoprogenitor), osteoblast cells, osteoclasts, and osteocytes. Osteogenic cells are pluriprotein stem cells that have not been differentiated and originate from mesenchymal system. Osteoblast cells are cells that function in the process of bone formation. Osteoblasts will produce, secrete, and precipitate new organic matrix elements called osteoid. Osteoid is a bone matrix that has not undergone calcification, which is newly formed, and does not contain minerals since after osteoid deposition will occur mineralization and become 


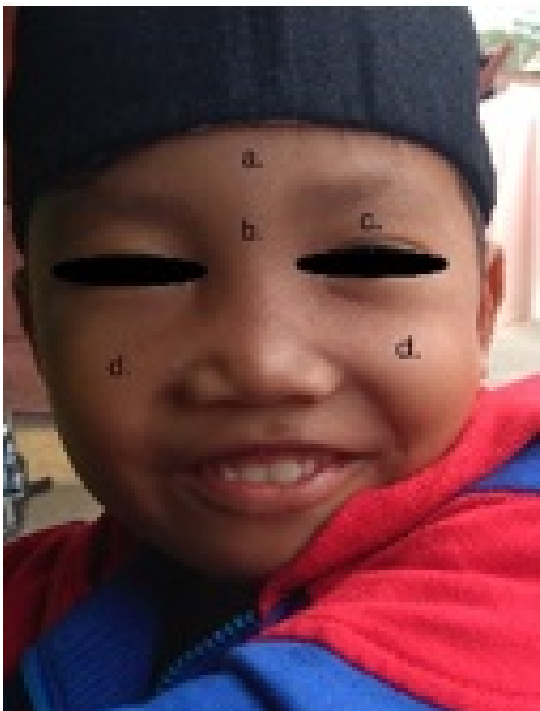

Figure 1 The clinical features of the Cooley-face: A. Broad forehead, B. Short nose (pug) in the presence of nasal bridge depression and no nasal base, wide space between two eyes, C. ocular protrusion, swollen eyelids, eyelid folds, D. cheekbones rising (protruding), the maxilla looks more protusive

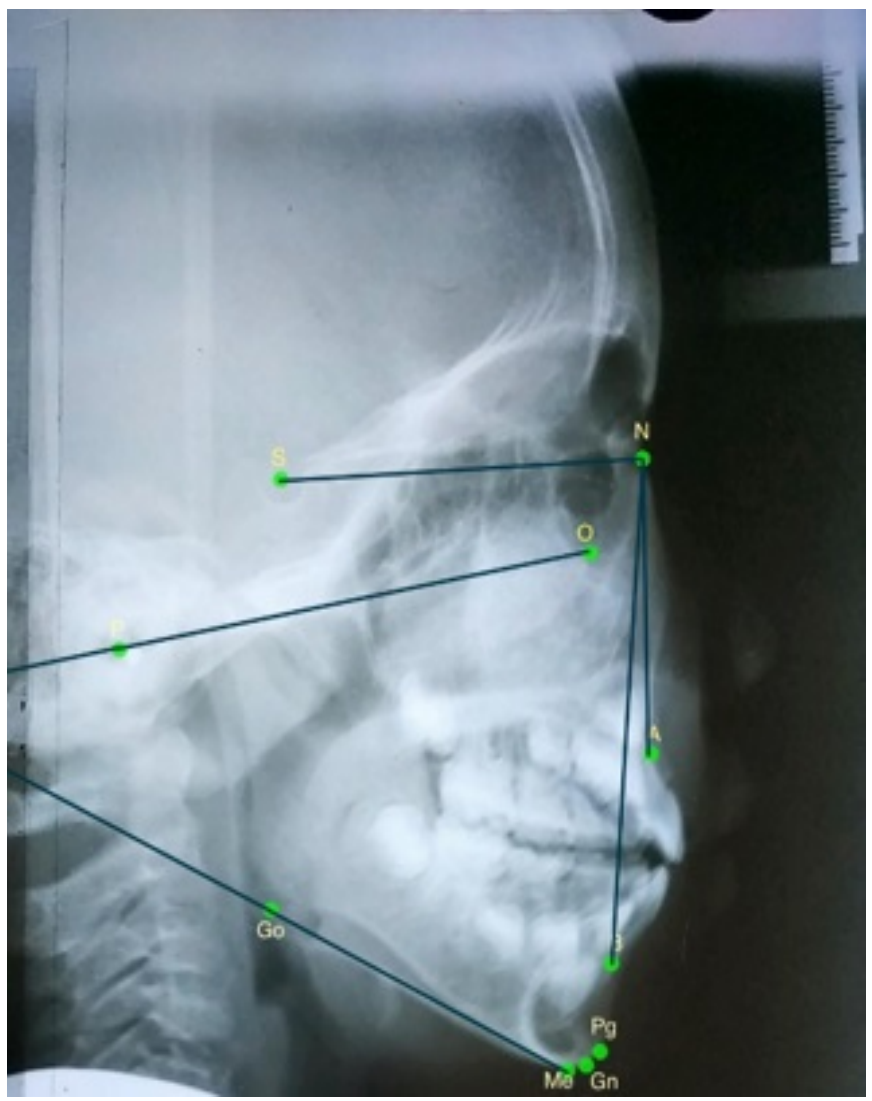

Figure 2 Cephalometri analysis: $\angle \mathrm{SNA}=86^{\circ} ; \angle \mathrm{SNB}=81^{\circ}$; $\angle$ ANB $=5^{\circ}$; and $\angle$ FH-Man $($ PO-GoMn $)=35^{\circ}$ bone. Osteoclasts are cells that cause bone resorption, in the form of substantial multinuclear cells located along the bone surface that occur resorption, remodeling, and bone repair. Osteocytes or bone cells which are osteoblasts recondited in the bone matrix. Osteoblast cells, osteoclasts, and osteocyte cells will cooperate in the process of bone remodeling. ${ }^{4-6}$

\section{Case Report}

A 5-year-old child came to RSGM with his mother due to examination of his teeth. Patient was diagnosed with thalassemia $\beta$ major since 1 year old and already performed routine blood transfusions every month. Intraoral examination showed pale oral mucose (purplish), profound caries on 85th teeth exposed to pulp, overbite $4 \mathrm{~mm}$, overjet $3 \mathrm{~mm}$, and deep palatum. Extraoral examination result exhibited the typical face of thalassemia sufferers, namely cooley-face. The patient had pug-look nose without the base of the nose, the distance between the two eyes was wide, the forehead was wide, the cheek bone thickened. Follow-up instruction was to order cephalo $\mathrm{x}$ ray to see the direction of cranial growth. The result of the cephalo $\mathrm{x}$-ray showed a protrusion of zygomatic bone, SNA angle $=86^{\circ}$, SNB angle $=81^{\circ}$, FHP-Man angle $=33^{\circ}$, cortical bone thinning, short and large teeth.

Based on clinical examinations performed on patients showed the characteristics of cooley-face, specifically puggy nose without its base, the wide distance between two eyes, the width of the forehead bone, the thickening of the cheekbones so that the cheekbones look firm. The gingivae in the patient appears pale, the inner palatum is due to the effect of breathing habits using the mouth, partial incisor eruption seen in labioversion form, and $4 \mathrm{~mm}$ overbite. The fissure pit in the first permanent molar appears deeper and has deep exposed caries pulp of one of the immature permanent molars. There is enlargement of the cranial diploe and frontal bone protrusion. This can be seen on $\mathrm{x}$-ray. The description of hair-onend cannot be seen on $\mathrm{x}$-ray result because there is a mistake from taking $\mathrm{x}$-ray, one of a kind is films cutting. The results of this examination indicates the similarity of clinical findings that perfoms in patients with a thalassemia $\beta$ major with existing theories. Based on the Cephalo-tracing $\mathrm{x}$-ray result, the results were $\angle \mathrm{SNA}=86^{\circ}, \angle \mathrm{SNB}=81^{\circ}, \angle \mathrm{ANB}=$ $5^{\circ}$, and $<\mathrm{FH}-\mathrm{Man}=35^{\circ}$. 


\section{Discussion}

Thalassemia is a blood disorder that will cause bone abnormalities. This bone disorder occurs due to hypertrophy and erythrocyte marrow expansion which will later cause dilation in the bone marrow, thinning cortex and later osteoporosis will occur. The most frequent bone alteration seen in thalassemia are the cranium and facial bones. The cephal shape of thalassemia patients will become larger since there is a protrusion on the frontal bone and enlarged diploe in the cranium several times greater than normal people. This enlargement represents a spiky short haircut-like or hair-on-end on $\mathrm{x}$-ray. ${ }^{13}$

The face of thalassemia sufferers generally has a distinctive face, namely Cooley-face. This is due to a disturbance in the development of facial and cranium bones. The clinical features of the Cooleyface are as follows: ocular protrusion, swollen eyelids, eyelid folds, short nose (pug) in the presence of nasal bridge depression and no nasal base, cheekbones rising (protruding), wide space between two eyes, the maxilla looks more protusive, and broad forehead. Clinical symptoms in patients with thalassemia will appear lighter when blood transfusion therapy is successful..$^{7-9}$

The obvious oral manifestation in thalassemia sufferers is the presence of hypertrophy and remodeling of maxilla which often causes malocclusion. Overbite is more than $3 \mathrm{~mm}$ long with protusive and tenuous or prominent maxilla, yet crowding teeth. The posterior part undergoes a buccal discharge accompanied by an expansion of the alveolar process. ${ }^{11}$ The gingiva is seen to be inflamed with pale or purplish color. The color will be affected by the duration of blood transfusion. Many thalassemia sufferers have a bad habit to breath using the mouth which causes deep palatum.

Teeth also have morphological change, such as decreased bucolingual diameter, small second molars and premolars and increased amount of curves, pits and fissures. Enamel and dentin teeth contain iron with a higher concentration. This is related to the quantity of blood transfusions each year. The presence of iron overload from intensive blood transfusion regiments can cause Sika Syndrome, as well as parotid gland pain and swelling. This is a result of iron accumulation in the serous gland. Glossodinia and loss of tongue papillae are quite similar to those that occur in iron deficiency anemia and folic acid deficiency and also are frequent comorbidities of minor thalassemia.

Based on cephalometric analysis, if $\angle \mathrm{SNA}$ is more than $82^{\circ}$, it indicates anterior or maxillary protrusion, if $\angle \mathrm{SNB}$ is more than $80^{\circ}$, indicating anterior or maxillary protrusion. Thus, based on the $\mathrm{x}$-ray result, there is maxillary bone growth excessive towards the anterior causing protusive appearance. ANB angle is the angle that describes the skeletal relation between the maxilla and mandibular. The normal angle of $<$ ANB is $2^{0}$ or is included in category I the skeletal class. If the angle $\mathrm{ANB}>2^{0}$ then it indicates the tendency of skeletal class II, whereas if the angle of $\mathrm{ANB}<0^{\circ}$ then it shows the tendency of skeletal class III. ANB angle can be obtained by reducing the angle of SNA and the angle. ${ }^{7}$ Based on the radiographic results it can be seen that patients with thalassemia have skeletal class II tendency and there is more anterior or protusive appearence of maxillary growth.

\section{Conclusion}

Thalassemia sufferers have oral manifestations which are characterized by cooley-face, namely puggy nose without its base, the wide distance between two eyes, the width of the forehead bone, the thickening of the cheekbones so that the cheekbones look firm. The gingivae in the patient appears pale, the inner palatum is due to the effect of breathing habits using the mouth, partial incisor eruption seen in labioversion form and $4 \mathrm{~mm}$ overbite. Based on the radiographic results it can be seen that patients with thalassemia have skeletal class II tendency and there is more anterior or protusive appearence of maxillary growth.

\section{Aknowledgment}

I would like to thank all the Lecturer Departement of Oral Biology for guiding and helping me until the completion of this article.

\section{Conflict of Interest}

The authors report no conflict of interest.

\section{References}

1. Mustafa MA, Thiru EM. IIzam HF, et al. Pathophysiology clinical manifestation and carrier detection in thalessemia. IOSR J Dent \& Med Sci 2016;15: 122-126.

2. Brown BA. Hematology principles and prosedures. 3rd ed. Philadelphia: Lea \& Febiger; 1980.

3. Cunningham MJ, Macklin EA, Neufeld EJ. Thalassemia Clinical Research Network. Complications of BetaThalassemia Major in North America. Blood 2004;104: 34-39. 
4. Orgna C, Rugolotto S, De Stefano P, et al. Survival and complications in patients with thalassemia major treated with transfusion and deferoxamine. Haematologica 2004;89: 1187-1193.

5. Gaudio A, Morabito N, Xourafa A, et al. Bisphosphonates in the treatment of thalassemia-associated osteoporosis. J Endocrinol Invest 2008;31: 181-184.

6. Burgest TS, Qian Y, Kaufman. The ligand for osteoprotegerin (OPGL) directly activates mature osteoclast. J Cell Boil 1999;145; 527-537.

7. Singh, G. Textbook of orthodontics. New Dhelhi: Jaype Brothers Medical Publisher; 2007.

8. Ragab LA, Hamdy MM, Shaheen IA, et al. Blood transfusion among thalassemia patients: a single egyptian center Eexperience. Asian J Transfus Sci 2013;7: 33-36.

9. Domellöf M, Dewey KG, Lönnerdal B, et al. The diagnostic criteria for iron deficiency in infants should be reevaluated. J Nutrion 2002;132: 3680-3686.

10. Kelleher SL. Effects of age and mineral intake on the regulation of iron absorption in infants. J Pediatr 2006;149: 69-73
11. Perrotta S, Cappellini MD, Bertoldo F, et al. Osteoporosis in $\beta$-thalassemia major patients: analysis of the genetic background. Br J Haematol 2000;111: 461-466.

12. Dresner Pollack R, Rachmilewitz E, Blumenfeld A, et al. Bone mineral metabolism in adults with $\beta$-thalassemia major and intermedia. Br J Haematol 2000;111: 902-907.

13. Galanello R, Raffaella O. Beta thalassemia. Orphanet J Rare Diseases 2010;5; 156-163.

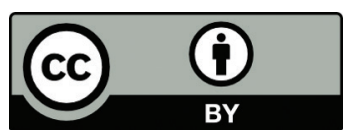

This work is licensed under a Creative Commons Attribution 